\title{
The effects of hyperglycemia on the biological behavior of human gingival fibroblasts on a titanium surface
}

\author{
Yan-Yan Liu ${ }^{1}$, Rong-Jian $\mathrm{Lu}^{2}$, Biao Guo ${ }^{2}$, Lin-Lin Gao ${ }^{3}$, Nan Zhang ${ }^{1}$, Wen-Xiao Chang ${ }^{1}$ \\ ${ }^{1}$ Department of Stomatology, Shanxi Bethune Hospital, Shanxi Academy of Medical Sciences, Tongji Shanxi Hospital, Third Hospital of Shanxi \\ Medical University, Taiyuan, China; ${ }^{2}$ Department of Stomatology, Fifth Medical Center of Chinese PLA General Hospital, Beijing, China; \\ ${ }^{3}$ Department of Endocrinology, Shanxi Bethune Hospital, Shanxi Academy of Medical Sciences, Tongji Shanxi Hospital, Third Hospital of Shanxi \\ Medical University, Taiyuan, China \\ Contributions: (I) Conception and design: YY Liu, N Zhang; (II) Administrative support: WX Chang; (III) Provision of study materials or patients: \\ RJ Lu; (IV) Collection and assembly of data: B Guo; (V) Data analysis and interpretation: LL Gao; (VI) Manuscript writing: All authors; (VII) Final \\ approval of manuscript: All authors. \\ Correspondence to: Wen-Xiao Chang; Nan Zhang. Department of Stomatology, Shanxi Bethune Hospital, Shanxi Academy of Medical \\ Sciences, Tongji Shanxi Hospital, Third Hospital of Shanxi Medical University, No. 99 Longcheng Street, Xiaodian District, Taiyuan, China. \\ Email: wener999-111@163.com; zhangnan19770718@sina.com.
}

Background It is well known that diabetes mellitus is one of the high-risk factors for periodontitis and also for the failure of implant restorations. Usually, the success of an implant restoration depends on both the good osseointegration and the stable soft tissue interface on the implant neck. A good gingival interface of the implant neck is the barrier that enables implant to resist oral microorganisms and the site of initiation of peri-implantitis. This study sought to investigate the effects of hyperglycemia on the attachment and proliferation of human gingival fibroblasts (HGFs) on pure titanium surfaces.

Methods: HGFs were cultured in cell culture mediums with different glucose concentrations (i.e., 5.5, 8. 8, 10 , and $15 \mathrm{mmol} / \mathrm{L}$ ) for $7 \mathrm{~d}$ and seeded on pure titanium surfaces. The cells that were seeded on the titanium surfaces had been cultured in cell culture mediums with different glucose concentrations for 3 and $7 \mathrm{~d}$. The attached HGFs on the titanium surfaces were counted for all groups using a blood cell counting plate, and the results were statistically analyzed. The morphologies of the attached HGFs on the titanium surfaces were observed for all the groups using a scanning electronic microscope.

Results: As the glucose concentrations increased, the number of attached HGFs on the titanium surfaces decreased. The numbers of attached cells in Groups A and B $7 \mathrm{~d}$ after being seeded on the titanium surfaces were more than those $3 \mathrm{~d}$ after being seeded $(\mathrm{P}<0.05)$. The numbers of attached cells in Groups $\mathrm{C}$ and $\mathrm{D}$ $3 \mathrm{~d}$ after being seeded on the titanium were more than those $7 \mathrm{~d}$ after being seeded $(\mathrm{P}<0.05)$. The scanning electronic microscope showed that the attached cells in Groups A and B proliferated well, and most cells grew one on top of another. Conversely, the attached cells in Groups C and D proliferated sparsely and the cell morphologies were not good.

Conclusions: The attachment and proliferation of HGFs on pure titanium surfaces were inhibited by increases in glucose concentrations, and the inhibition was further enhanced by the passage of time.

Keywords: Hyperglycemia; gingival fibroblast; titanium

Submitted Jul 06, 2021. Accepted for publication Sep 09, 2021.

doi: 10.21037/apm-21-2277

View this article at: https://dx.doi.org/10.21037/apm-21-2277 


\section{Introduction}

The long-term stability of an implant in the oral cavity not only depends on good and stable osseointegration, but also on the soft tissue interface of the implant neck. The attachment of an implant of a soft-tissue interface has a structure that is similar to that of natural dental epithelium which is composed of well-proliferating fibroblast and organic matrix secreted by fibroblast. The formation of a tight epithelial bond is the first functional biological sealing barrier that enables an implant to resist pathogenic microorganisms in the oral cavity (1). Diabetes mellitus is a risk factor affecting the success of implant repair. Most previous studies on the effects of diabetes mellitus on implant restoration have focused on bone consolidation; however, very little research has been conducted on the effects of diabetes mellitus on the implant neck and gingival tissue $(2,3)$. In this study, human gingival fibroblasts (HGFs) were cultured in vitro in a hyperglycemic environment and seeded on a pure titanium surface. Changes in the numbers and growth morphologies of the HGFs at different culture times were then observed. The results of this study provide a theoretical reference for dentists to choose the best time for implant repair in clinical practice for diabetic patients.

We present the following article in accordance with the MDAR reporting checklist (available at https://dx.doi. org/10.21037/apm-21-2277).

\section{Methods}

\section{Materials and equipment}

The following materials and equipment were used: HGF cell line (Shanghai Jiahe Technology Biological Company), fetal bovine serum (FBS; Gibco, USA), Dulbecco's Minimal Essential Medium (DMEM) (Gibco, USA), $0.25 \%$ Trypsin (Gibco, USA), dedicated electron microscope fixing solution, $3.7 \%$ glutaraldehyde-1.5\% paraformaldehyde (Sigma, USA), a carbon dioxide $\left(\mathrm{CO}_{2}\right)$ constant temperature incubator (MCO-15AC, SANYO, Japan), cell culture dishes, cell culture flasks (Corning, USA), an inverted microscope (IX 51, Olympus, Japan), low-speed centrifuge (5702R, Eppendorf, USA), an automatic microplate reader (MULTISKAN MK3, Thermo, USA), a Critical Point Dryer (Leica EM CPD300, Leica Company, Germany), and a scanning electron microscope (VEGA3LMU, TESCAN company, Czech Republic).

\section{Experimental metbod}

\section{Preparing high-glucose culture mediums}

To prepare the high-glucose culture mediums, ordinary DMEM medium was added with a certain amount of L-glucose. The glucose concentrations for the culture mediums were as follows: $5.5 \mathrm{mmol} / \mathrm{L}$ (Group A), $8.8 \mathrm{mmol} / \mathrm{L}$ (Group B), $10 \mathrm{mmol} / \mathrm{L}$ (Group C), and $15 \mathrm{mmol} / \mathrm{L}$ (Group D). The osmotic pressure was 274$302 \mathrm{mOsm} / \mathrm{kg} \cdot$ dihydrogen monoxide $\left(\mathrm{H}_{2} \mathrm{O}\right)$.

\section{Producing pure titanium specimens}

To produce the pure titanium specimens, a finished pure titanium rod was cut with a cross section of $10 \mathrm{~mm} \times 10 \mathrm{~mm}$ square into 48 cubic specimens with a thickness of $3 \mathrm{~mm}$. The $10 \mathrm{~mm} \times 10 \mathrm{~mm}$ side was chosen as the observation section. The titanium surface roughness and morphology require as follows. The observation section was polished flat with a diamond grinding bur and a rubber wheel. A 600\# flannel wheel was used to polish the observation section to a surface roughness $(\mathrm{Ra})$ of $0.1 \mu \mathrm{m}$. Zirconia particles with particle size of $30-50 \mu \mathrm{m}$ were used to sandblast the observation sections of the 48 pure titanium specimens with a sandblasting pressure of 2 bar, and the observation section was treated to a uniform, gray, rough surface. All specimens were cleaned with a high-pressure steam cleaner to remove dirt particles, and ultrasonically oscillated with $95 \%$ ethanol solution 3 times for 10 minutes each time. They were then packed in $3 \mathrm{M}$ plastic bags, and sterilized in autoclaved steam for use.

\section{Cell strain culturing and inoculating}

The HGF cell lines were cultured in DMEM supplemented with $10 \%$ FBS for 48 hours (with 1 fluid change), and subcultured until generation 5 . The cells were prepared to $4.0 \times 10^{4}$ piece $/ \mathrm{mL}$ cell suspension for the experiments. The cells were inoculated in equal amounts of cell suspensions in four different sets of glucose medium, and after continued incubation for 7 days. All cells were treated with trypsin to a uniform cell suspension, the trypsin cells from each group to a uniform cell suspension for use. The gray roughened side of the sterilized pure titanium specimens were placed upwards in 24-pore culture plates, and $0.1 \mathrm{~mL}$ of the cell suspension was taken and cultured for $7 \mathrm{~d}$ for inoculation on the titanium surface. There were 12 specimens in each group. Fresh culture solution corresponding to the glucose concentration was replaced every $12 \mathrm{~h}$, and after continual culturing for 3 and $7 \mathrm{~d}$, respectively, the 6 specimens in 
Table 1 Comparison of quantities of attached HGFs in all groups 3 and $7 \mathrm{~d}$ after being seeded on titanium

\begin{tabular}{lccccc}
\hline Group & $\mathrm{n}$ & $3 \mathrm{~d}$ & $7 \mathrm{~d}$ & $t$ \\
\hline Group A: $5.5 \mathrm{mmol} / \mathrm{L}$ & 15 & $15.23 \pm 0.776$ & $21.00 \pm 1.134$ & 10.511 & 0.000 \\
Group B: $8.8 \mathrm{mmol} / \mathrm{L}$ & 15 & $12.83 \pm 0.556$ & $18.20 \pm 0.528$ & 15.007 & 5.499 \\
Group C: $10 \mathrm{mmol} / \mathrm{L}$ & 15 & $6.30 \pm 0.797$ & $3.97 \pm 0.611$ & 0.001 \\
Group D: $15 \mathrm{mmol} / \mathrm{L}$ & 15 & $1.77 \pm 0.417$ & $0.24 \pm 0.111$ & -23.125 & - \\
F & - & 131.467 & 54.961 & - \\
P & - & 0.000 & 0.000 & - \\
\hline
\end{tabular}

HGFs, human gingival fibroblasts.

each group (5 for counting and 1 for scanning electron microscope SEM observation) were observed.

\section{Counting the attached cells on the titanium surface}

The attached cells on the surface of the 5 titanium specimens from each group were treated with trypsin for 5 minutes. And the digested cells were then blown down with fresh culture solution to achieve cell suspension. The blood cell counting plate was cleaned and covered with a slip. The cover slip was then put on the counting plate, and a straw was used to suck the appropriate amount of cell suspension drop to the edge of the cover slip to make the suspension fill between the cover slip and the blood cell counting plate. It was then left to stand for $3 \mathrm{~m}$. Notably, no bubbles were allowed to appear under the cover slip, and the suspension was not allowed to enter the beside gutter. The total number of cells per large grid were counted for the counting plate. The line-imposing cells were only counted for the left and upper side. The following formula was used: number of cells $/ \mathrm{mL}=\mathrm{N}$ total number of large grid cells $/ \mathrm{N} \times 10^{4}$. The attached cells on the surface of each titanium specimen were repeatedly counted 3 times to obtain 15 numerical values, and the average for the comparative analysis was then taken.

\section{Growth-morphology electron microscopy observation of the attached cells on the titanium surfaces}

Four titanium specimens were taken from each group after 3 and $7 \mathrm{~d}$ of inoculating and culturing. They were rinsed 2 times with pure water, and fixed with an electron microscopy specialized fixative solution of $3.7 \%$ glutaraldehyde- $1.5 \%$ paraformaldehyde for $15 \mathrm{~m}$, and washed 3 times with distilled water for 2 minutes each time. Next, $30 \%, 50 \%, 70 \%, 90 \%, 95 \%$, and $100 \%$ alcohol were used for dehydration for $3 \mathrm{~m}$ each time. They were left to dry at the critical point, and then sputtered and scanned for observation.

\section{Statistical methods}

The SPSS13.0 software package was used for the statistical analysis. One-way analysis of variance was performed on the surface attached cell count results of each group of specimens at different times, and group $t$-tests were performed on the surface attached cell counting results of the same group at different inoculation times. $\mathrm{P}<0.05$ means was considered statistically significant.

\section{Results}

\section{Effects of glucose concentration on the number of attached cells}

The number of HGFs that attached to the titanium surface in Group A was higher than that in other groups, and the number in Group D was lower than that in other groups for 3 and $7 \mathrm{~d}$. The difference was statistically significant $(\mathrm{P}<0.05$; see Table 1).

\section{Effects of attachment time on the number of attached cells}

The numbers of attached cells after the HGFs were seeded on the titanium surfaces at the concentrations for Groups $\mathrm{A}$ and $\mathrm{B}$ for $7 \mathrm{~d}$ were higher than those of the cells seeded for $3 \mathrm{~d}$; the difference was statistically significant $(\mathrm{P}<0.05)$. However, for Groups C and D, the opposite results were found; the difference was statistically significant $(\mathrm{P}<0.05$; see Table 1). 


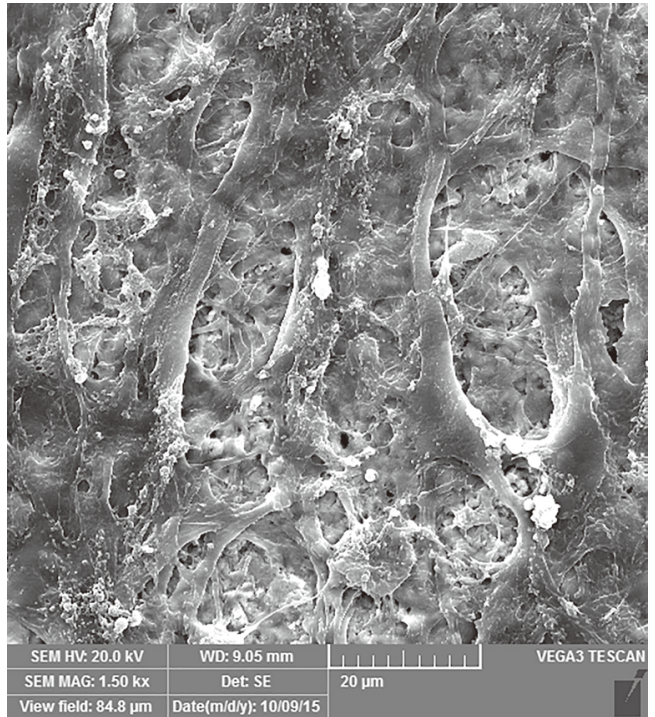

$5.5 \mathrm{mmol} / \mathrm{L}$

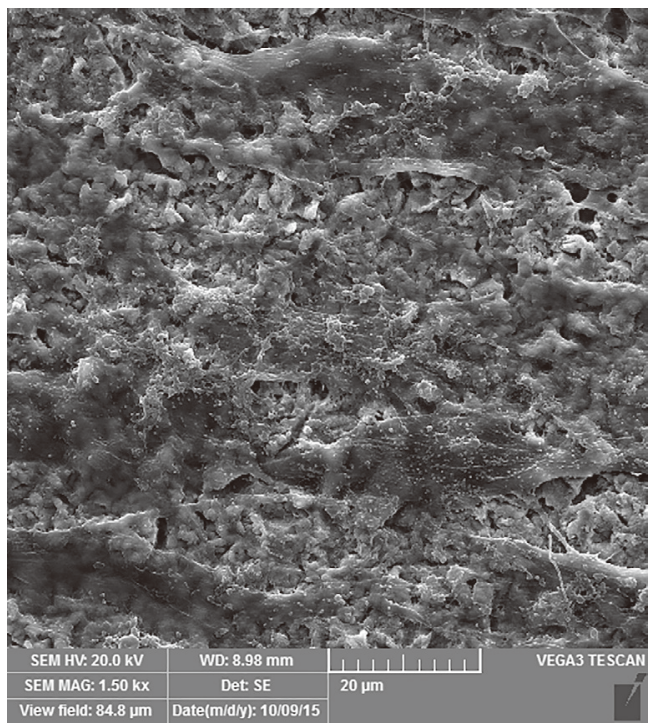

$10 \mathrm{mmol} / \mathrm{L}$

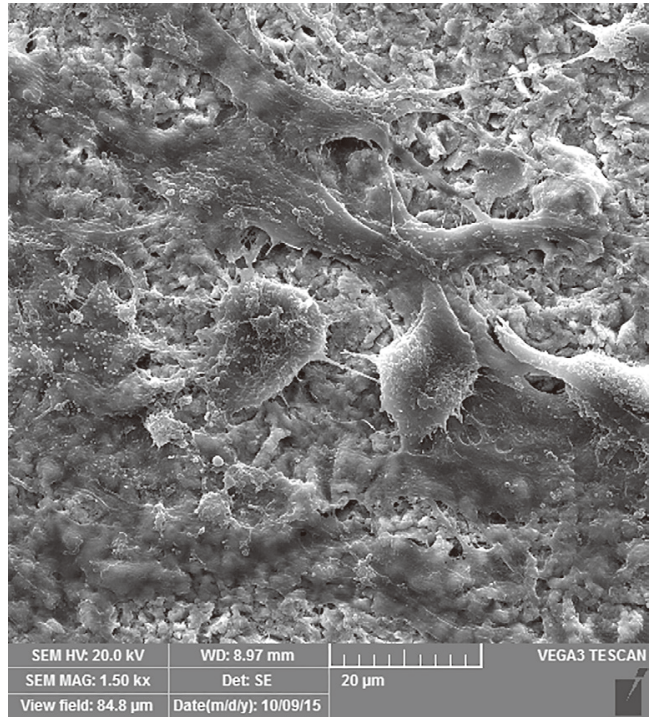

$8.8 \mathrm{mmol} / \mathrm{L}$

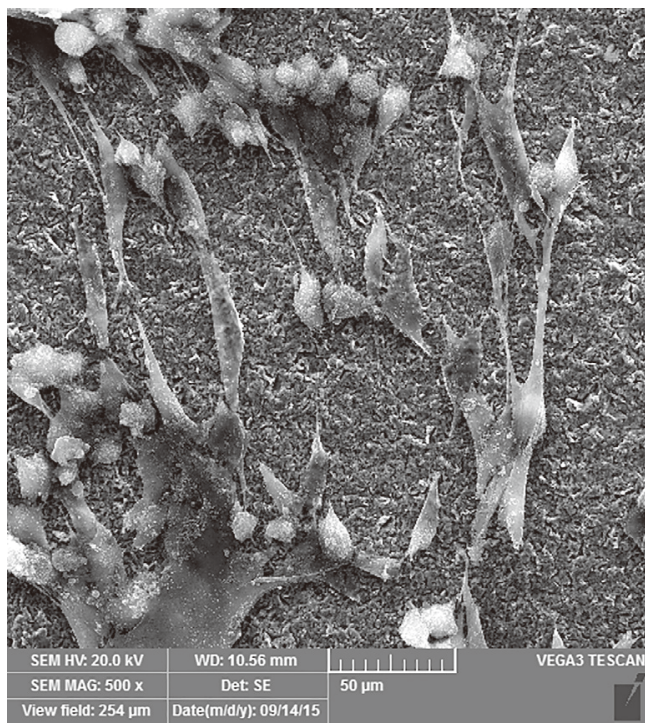

$15 \mathrm{mmol} / \mathrm{L}$

Figure 1 Morphology of HGFs cultured with different glucose concentrations $3 \mathrm{~d}$ after being seeded on titanium. HGFs, human gingival fibroblasts.

\section{Observing HGFs on the titanium surfaces using a scanning electron microscope}

The HGFs that attached to the titanium surfaces in Groups $\mathrm{A}$ and $\mathrm{B}$ showed good adherence and growth. Further, the cells had clear contours and various morphologies, such as spindle, triangular and polygonal shapes, and 2-4 cell cytoplasmic processes. Additionally, the cells extended obviously and intersected with each other in a fence-shape and reticular structure, and most cells showed stacked growth on the titanium surfaces. In Groups $\mathrm{C}$ and $\mathrm{D}$, the numbers of attached HGFs on the titanium surfaces were scarce and mostly non-extensive. Further, the cells had an atrophic shape and poor cell growth morphologies (see Figures 1,2).

\section{Discussion}

Fibroblasts are the main constituent cells of gingival connective tissue and one of the main repair cells of 


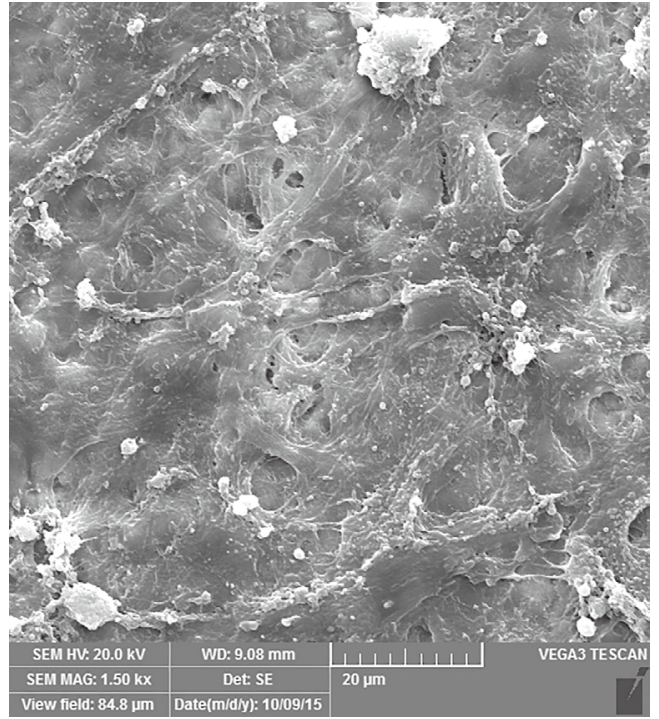

$5.5 \mathrm{mmol} / \mathrm{L}$

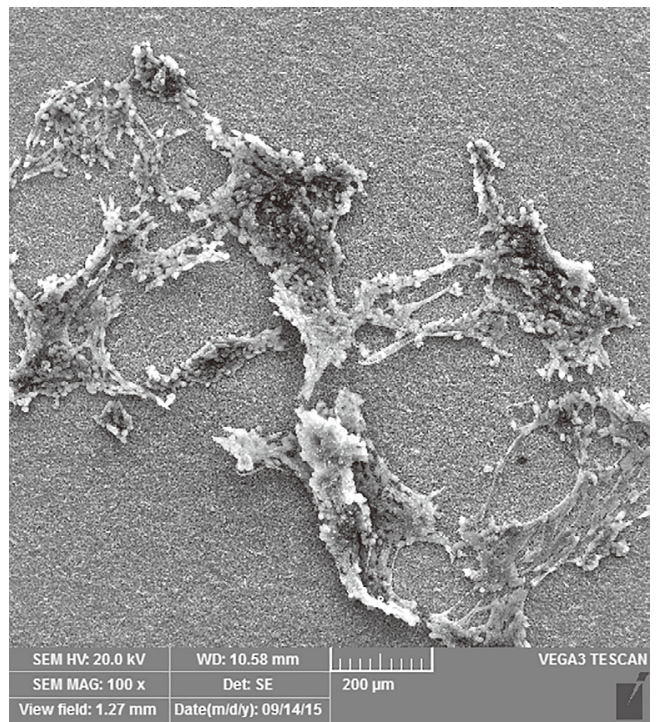

$10 \mathrm{mmol} / \mathrm{L}$

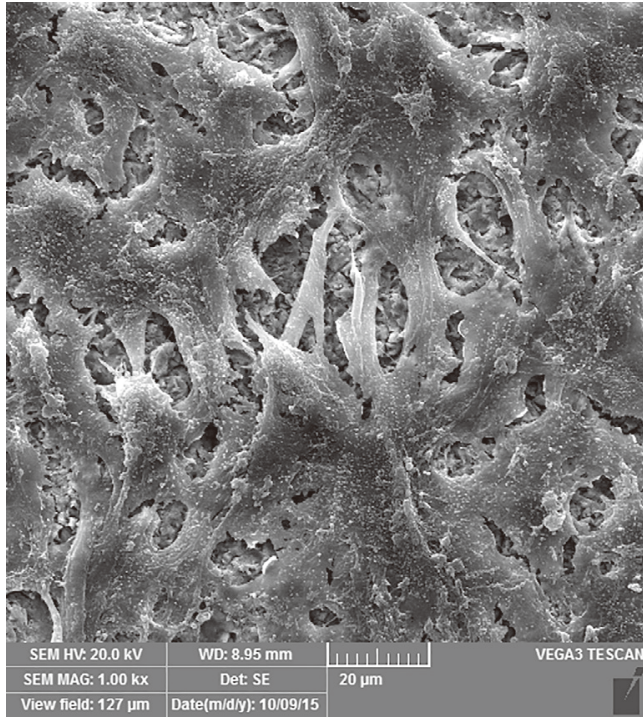

$8.8 \mathrm{mmol} / \mathrm{L}$

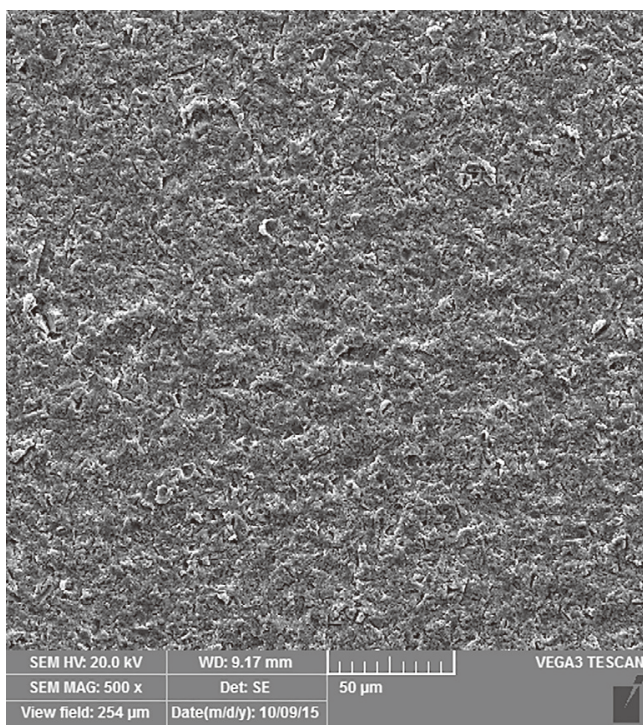

$15 \mathrm{mmol} / \mathrm{L}$

Figure 2 Morphology of HGFs cultured with different glucose concentrations $7 \mathrm{~d}$ after being seeded on titanium. HGFs, human gingival fibroblasts.

periodontal tissue remodeling. Fibroblasts play an important role in wound repair through migration, proliferation, and collagen secretion. Good gingival sealing quality has a strong mechanical resistance, which can largely prevent lesion and infection of osseous interface. The interface between an implant and the gingival soft tissue has a structure similar to the attachment of natural tooth epithelium, and forms a tight epithelial "cuff". This cuff becomes the first functional biological sealing barrier, and it is this barrier that enables an implant to resist pathogenic microorganisms in oral cavity. It is generally believed that this barrier is largely formed by the adhesion of the gingival epithelium binding to the surface of the implant (1). Peri-implantitis starts with the destruction of the soft tissue interface of the implant neck, which is one of the main reasons for the failure of implant restoration. The pathogenesis and treatment methods are similar to those of periodontitis. A large number of studies have confirmed that diabetes mellitus patients with bad oral hygiene are susceptible to periodontal infection, and the incidence and 
degree of periodontitis in patients with hyperglycemia are higher than those in people with normal blood glucose (4-6). The reason is that glycosylation end products in patients with hyperglycemia periodontitis weaken the defense and recovery ability of gingival fibroblasts, which leads to collagen degradation and extracellular matrix destruction, which in turn leads to the destruction of periodontal tissue and the mediation of the development of periodontal disease in patients with hyperglycemia.

In the present study, HGFs were cultured in cell culture mediums with glucose concentrations of 5.5, 8.8, 10,15 , and $20 \mathrm{mmol} / \mathrm{L}$ in a simulated hyperglycemia environment in vitro, and pure titanium specimens with a surface roughness of 30-50 um were prepared by imitating the actual surface characteristics of an implant neck according to the requirements of the surgical indications on blood glucose in clinical practice and the diagnostic criteria of diabetes mellitus in endocrinology to ensure the experimental conditions were close to the actual clinical implant-soft tissue combination. The results showed that when the glucose concentration had a blood glucose value of $8.8 \mathrm{mmol} / \mathrm{L}$ required by surgical indications, the number of HGFs that attached to the roughened pure titanium surface was slightly lower than that of HGFs cultured in a normal glucose environment; however, the growth state of the cells on the pure titanium surface was similar. Thus, when the blood glucose value was below $8.8 \mathrm{mmol} / \mathrm{L}$, the attachment quality of gingival tissue to the implant surface was acceptable. However, when the glucose concentration was more than $10 \mathrm{mmol} / \mathrm{L}$, the number of HGFs that attached to the pure titanium surface decreased greatly. Further, the attached cells grew poorly and the cell bodies showed atrophy. When the glucose concentration was $20 \mathrm{mmol} / \mathrm{L}$, no HGFs attached to the pure titanium surfaces. Thus, the $20 \mathrm{mmol} / \mathrm{L}$ group was not included in the analysis and discussion.

Collagen I, collagen III, and fibronectin are important interstitial proteins that enable gingival fibroblasts and periodontal fibroblasts to adhere to the natural roots and the titanium surfaces of implants. The results of previous experiments $(7,8)$ have shown that there is no significant difference in the amount of HGF cell proliferation and the amount of collagen I (Col I), collagen III (Col III), and fibronectin (FN) secreted by HGF cells in culture environments with 5.5, 7 and $8.8 \mathrm{mmol} / \mathrm{L}$ glucose. Further, when the glucose concentration was higher than $8.8 \mathrm{mmol} / \mathrm{L}$, the amount of HGF proliferation decreased significantly, and the amount of Col I, Col III, and FN secreted by HGFs decreased significantly. In next experiments, we plan to explore what measures can be taken to increase the expression of Col I, Col III, and FN.

The results also showed that when the glucose concentration was below $8.8 \mathrm{mmol} / \mathrm{L}$, the number of HGFs that attached to the titanium surfaces for $7 \mathrm{~d}$ was significantly more than that for $3 \mathrm{~d}$. Additionally, when the glucose concentration was above $8.8 \mathrm{mmol} / \mathrm{L}$, the number of HGFs that attached to the titanium surface for $7 \mathrm{~d}$ was significantly less than that for $3 \mathrm{~d}$. This suggests that for patients whose blood glucose is below the threshold required for implant surgery indications, the sealing quality of implant cuff can be improved by increasing the healing time; however, for those with high blood glucose, it is impossible to achieve the reliable attachment of gingival junctional epithelium by prolonging the healing period after implantation.

This in vitro experiment cannot fully simulate the internal environment. In this study we have discussed the effects of glucose concentrations on attachment of HGFs on titanium. However, there are many factors which can influence implant-gingiva interface, such as blood glucose, hormones, immunity, trauma, etc. (9). To enhance fibroblast function, besides controlling blood sugar in the internal environment of human body, diabetics could maintain good oral hygiene to decrease the amount of oral pathogenic microorganisms, and Immunity of diabetics could be regulated to alleviate the destruction of periodontal tissue. The effects of other factors on implant-gingiva interface will be explored in follow-up experiments.

\section{Acknowledgments}

Funding: None.

\section{Footnote}

Reporting Checklist: The authors have completed the MDAR reporting checklist. Available at https://dx.doi. org/10.21037/apm-21-2277

Data Sharing Statement: Available at https://dx.doi. org/10.21037/apm-21-2277

Conflicts of Interest: All authors have completed the ICMJE uniform disclosure form (available at https://dx.doi. org/10.21037/apm-21-2277). The authors have no conflicts 
of interest to declare.

Ethical Statement: The authors are accountable for all aspects of the work in ensuring that questions related to the accuracy or integrity of any part of the work are appropriately investigated and resolved.

Open Access Statement: This is an Open Access article distributed in accordance with the Creative Commons Attribution-NonCommercial-NoDerivs 4.0 International License (CC BY-NC-ND 4.0), which permits the noncommercial replication and distribution of the article with the strict proviso that no changes or edits are made and the original work is properly cited (including links to both the formal publication through the relevant DOI and the license). See: https://creativecommons.org/licenses/by-nc-nd/4.0/.

\section{References}

1. Guo T, Gulati K, Arora H, Han P, et al. Race to invade: Understanding soft tissue integration at the transmucosal region of titanium dental implants. Dent Mater 2021;37:816-31.

2. Shen Y, Guo S, Chen G, et al. Hyperglycemia Induces Osteoclastogenesis and Bone Destruction Through the Activation of $\mathrm{Ca} 2+/$ Calmodulin-Dependent Protein Kinase II. Calcif Tissue Int 2019;104:390-401.

3. Yamazaki S, Masaki C, Nodai T, et al. The effects

Cite this article as: Liu YY, Lu RJ, Guo B, Gao LL, Zhang N, Chang WX. The effects of hyperglycemia on the biological behavior of human gingival fibroblasts on a titanium surface. Ann Palliat Med 2021;10(9):9685-9691. doi: 10.21037/apm-212277 of hyperglycaemia on peri-implant tissues after osseointegration. J Prosthodont Res 2020;64:217-23.

4. Preshaw PM, Alba AL, Herrera D, et al. Periodontitis and diabetes: a two-way relationship. Diabetologia 2012;55:21-31.

5. Maekawa S, Katagiri S, Takeuchi Y, et al. Bone metabolic microarray analysis of ligature-induced periodontitis in streptozotocin-induced diabetic mice. J Periodontal Res 2017;52:233-45.

6. Sanz M, Ceriello A, Buysschaert M, et al. Scientific evidence on the links between periodontal diseases and diabetes: Consensus report and guidelines of the joint workshop on periodontal diseases and diabetes by the International Diabetes Federation and the European Federation of Periodontology. J Clin Periodontol 2018;45:138-49.

7. Chang W, An Y, Zhang H, et al. Effects of different glucose concentrations on the proliferation of human gingival fibroblasts in vitro. Chinese Remedies \& Clinics 2016;16:164-5.

8. Zhang J, An Y, Gao LL, et al. Effect of high glucose on biological activity of human gingival fibroblasts. Chinese Remedies \& Clinics 2016;16:176-7.

9. Shi X, Xu L, Munar ML, et al. Hydrothermal treatment for TiN as abrasion resistant dental implant coating and its fibroblast response. Mater Sci Eng C Mater Biol Appl 2015;49:1-6. 